\title{
The Nitrate Reductase Assay in the Rapid Detection of Multidrug-Resistant and Extensively Drug- Resistant Tuberculosis in South Gujarat, India
}

\author{
Singh Shruti S. ${ }^{1}$, Desai Pratibha B. ${ }^{2}$ \\ ${ }^{1,2}$ Department of Microbiology, Shree Ram Krishna Institute of Computer Education and Applied Sciences, Surat; Veer Narmad South \\ Gujarat University, Surat, Gujarat, India
}

\begin{abstract}
Introduction: The burden of Tuberculosis (TB) particularly with multi-drug-resistance (MDR) is increasing worldwide and has become a major public health concern. The increasing prevalence of MDR as well as extensively drug-resistant (XDR) tuberculosis highlights the need for simple, rapid, affordable and accurate methods for performing drug susceptibility testing against first- line and second- line anti- TB drugs. Aims: To evaluate the performance of NRA in the rapid detection of multi-drug resistant and extensivelydrug resistant tuberculosis in the region of South Gujarat, India. Materials and Methods: 234 samples were collected from clinically suspected TB patients from South Gujarat Region, India and were subjected to microscopy examination by ZN method, culturing on Lowenstein-Jensen medium and drug susceptibility testing by indirect NRA. Indirect NRA was performed on the culture isolates and the results were compared with that of the Proportion method. Results: Out of these 234 samples, 94 were smear positive by Ziehl Neelsen (ZN) method (40.17\%) and 140 were smear negative. In case of culturing, out of 234 samples, 101 were culture positive (43.16\%) and 133 were culture negative. By performing First-Line DST, MDR-TB was detected in a total of 37/101 (36.63\%) and 35/101 (34.65\%) by both Proportion method and NRA respectively. By performing Second-Line DST, one case of XDR-TB was detected by both the methods. NRA results were available for 33 samples on day 7, 58 samples on day 10 and 10 samples on day 14 . As compared to Proportion method, the sensitivity of NRA was $87.5 \%$ and $100 \%$ and the specificity was $100 \%$ and $96.73 \%$ for RIF and INH respectively. Similarly, for $K$ and $O F$, the sensitivity of NRA was $71.42 \%$ and $76.92 \%$ and the specificity was $100 \%$ and $100 \%$ respectively. Conclusion: NRA is a simple, accurate, inexpensive and rapid method for detection of MDR and XDR-TB, especially in poor-resource countries, with limited laboratory facilities. The technique may become a valid substitute to traditional time consuming methods.
\end{abstract}

Keywords: Mycobacterium tuberculosis, multi-drug resistance, extensively-drug resistance, Proportion Method, Nitrate Reductase Assay

\section{Introduction}

Tuberculosis (TB) remains one of the world's deadliest communicable diseases. The disease caused by Mycobacterium tuberculosis resistant to two primary antitubercular drugs, rifampicin (RIF) and isoniazid (INH), is known as MDR-TB. The burden of tuberculosis (TB) particularly with multi-drug-resistance (MDR) is increasing worldwide and has become a major public health concern $[1$, 2]. According to the World Health Organization (WHO) report, most cases are estimated to be in Asia and Africa accounting for $58 \%$ and $27 \%$ respectively, with the highest incidence in India (range 2.0-2.4 million) and China (0.9 1.1 million), which together accounts for $38 \%$ of the total number of cases ( Global TB Report, 2013). Current resurrection of TB is mainly due to increasing incidence of resistance of $M$. tuberculosis strains to first-line and important second-line anti-TB drugs and the association of active TB disease with HIV co-infection or other underlying immunosuppressive conditions [3, 4]. Accurate and timely diagnoses of MDR-TB cases with adequate treatment regimens are the essential key elements to stop primary transmission of MDR- TB. The increasing prevalence of multidrug- resistant (MDR) and extensively drug-resistant (XDR) tuberculosis highlights the need for simple, rapid, affordable and accurate methods for performing drug susceptibility testing against first- line and second- line antiTB drugs.

Conventional culture method based on Lowenstein -Jensen (LJ) medium is still the most commonly used and inexpensive method for the growth of $M$. tuberculosis. Similarly, conventional drug susceptibility testing methods based on LJ medium are time consuming, requires up to 6 weeks giving results $[5,6]$. Commercial broth based systems and molecular tests have been developed to reduce the turnaround time, but are still too expensive thus preventing them from being adopted in low resource countries [7, 8]

For developing countries, it would be useful to have a simple and inexpensive method for early and proper detection of drug resistant $\mathrm{TB}$ cases for the effective management and control of TB.

Nitrate Reductase Assay (NRA), also called Griess Method [9], was first described by Angeby et al. [10]. It has been endorsed by the WHO for the rapid detection of MDR-TB [11]. NRA is a simple, rapid, low-cost, phenotypic method performed on solid media and is based on the ability of Mycobacterium tuberculosis to reduce nitrate to nitrite, the presence of which can be easily detected with specific reagent, so called Griess Reagent, that produce a color change [10].

The main aim of the present study was to evaluate the performance of Nitrate Reductase Assay in the rapid detection of multi-drug resistant and extensively-drug resistant tuberculosis in South Gujarat, India.

\section{Materials and Methods}

In this study, 234 samples, pulmonary or extrapulmonary, 


\section{International Journal of Science and Research (IJSR) \\ ISSN (Online): 2319-7064 \\ Index Copernicus Value (2013): 6.14 | Impact Factor (2015): 6.391}

were collected from clinically suspected TB patients from South Gujarat Region, India, for 18 months during June 2013 to December 2014. All mycobacterial investigations were carried out at the Microcare Tuberculosis Laboratory, Surat, which is accredited for carrying out culture and Drug Susceptibility Testing (DST) by the Central TB Division, Ministry of Health and Family Welfare, Govt. of India.

\section{Microscopy and Culture}

All the specimens were handled in class II bio safety cabinet in a bio-safety level (BSL) - 3 laboratory and were decontaminated by Modified Petroff's Method [12]. All the samples were subjected to microscopic examination by using the conventional Ziehl Neelsen method for detection of acid fast bacilli (AFB) and culturing. The smears were graded according to the number of bacilli, as per recommendations of the World Health Organization (WHO).

All the culture isolates were confirmed as Mycobacterium tuberculosis by their slow growth rate, colony morphology, and pigmentation, inability to grow on L-J media containing p-nitro benzoic acid (PNB), niacin positive and catalase negative tests [13].

\section{Drug Susceptibility Testing}

In this study, drug susceptibility testing (DST) was performed by Nitrate Reductase Assay and the performance was compared to that of the Conventional Lowenstein Jensen Proportion Method (LJPM). Since the LJ Proportion method is widely used across laboratories in India under RNTCP as a standardized method for DST, this method was used as a reference standard method in this study [14].

\section{LJ Proportion Method}

The Lowenstein - Jensen Proportion Method was carried out on solid LJ medium according to the standard operating procedure of RNTCP with the recommended critical concentrations of $40 \mu \mathrm{g} / \mathrm{ml}$ rifampicin, $0.2 \mu \mathrm{g} / \mathrm{ml}$ isoniazid, $2 \mu \mathrm{g} / \mathrm{ml}$ ofloxacin and $30 \mu \mathrm{g} / \mathrm{ml}$ kanamycin. LJ media were incubated at $37^{\circ} \mathrm{C}$ and read at 28 and 42 days [6].

\section{Nitrate Reduction Assay (NRA)}

The method was carried out as described by Angeby et al. [10]. This method is based on the ability of M. tuberculosis to reduce nitrate to nitrite, which is routinely used for biochemical identification of mycobacterial species. The presence of nitrite can easily be detected with specific reagent, Griess reagent, which produces a color change. The nitrate reduction assay uses the detection of nitrite as an indication of growth when used as a drug susceptibility test. The rifampicin, isoniazid, ofloxacin and kanamycin were added in the LJ medium at a concentration of $40 \mu \mathrm{g} / \mathrm{ml}$, $0.2 \mu \mathrm{g} / \mathrm{ml}, 2 \mu \mathrm{g} / \mathrm{ml}$ and $30 \mu \mathrm{g} / \mathrm{ml}$ respectively with $1000 \mathrm{mg} / \mathrm{L}$ potassium nitrate $\left(\mathrm{KNO}_{3}\right)$. The inoculum turbidity was adjusted to a McFarland tube no. 1 and diluted 1:10 in PBS. The Griess reagent mixture consisted of 1 part $50 \%$ concentrated hydrochloric acid $(\mathrm{HCl}), 2$ parts $0.2 \%$ sulfanilamide and 2 parts $0.1 \% \mathrm{n}$-1-naphthylethylenediamine dihydrochloride. For each strain, $200 \mu$ l of the undiluted suspension was inoculated into the drug containing medium and $200 \mu \mathrm{l}$ of the $1: 10$ dilution into the drug-free medium. All the media were incubated at $37^{\circ} \mathrm{C}$. After 7 days, $500 \mu \mathrm{l}$ of reagent mixture was added to one drug-free medium. If any color occurred, all the media were developed by the reagent mixture. If no color change was observed in the growth control medium, the medium was discarded, and the other two growth control media and the antibiotic-containing media were re-incubated. The procedure was then repeated at day 10, using the second growth control, and if needed, also at day 14 , using the last growth control medium.

\section{Statistical analysis}

The results of NRA and Proportion method were analyzed and their sensitivity (ability to detect true resistance) and specificity (ability to detect true susceptibility) were calculated using standard formula.

\section{Results}

In total, 234 samples were collected from TB suspected patients from South Gujarat region, India. Out of these 234 samples, 94 were smear positive by Ziehl Neelsen (ZN) method $(40.17 \%)$ and 140 were smear negative. In case of culturing, out of 234 samples, 101 were culture positive on Lowenstein-Jensen medium (43.16\%) and 133 were culture negative [Table 1]. In total $101 \mathrm{~TB}$ positive patients, 70 were males $(69 \%)$ and the rest 31 were females $(31 \%)$. The youngest patient included in the study was 9 years old while the oldest was 86 years old. The maximum number of patients were found to be in the age-group of 20-29 $(31.68 \%)$, followed by in the age-group of $30-39(24.75 \%)$.

Table 1: Comparison of results of Microscopy Versus Culture on LJ medium

\begin{tabular}{|c|c|c|c|}
\hline \multicolumn{4}{|c|}{$\begin{array}{c}\text { Comparison of results of Microscopy versus culture on LJ } \\
\text { medium }\end{array}$} \\
\hline & Smear +ve & Smear -ve & Total \\
\hline Culture +ve & 94 & 7 & 101 \\
\hline Culture -ve & 0 & 133 & 133 \\
\hline Total & 94 & 140 & 234 \\
\hline
\end{tabular}

Table 2: Primary Culture results

\begin{tabular}{|c|c|c|}
\hline Sr. No. & Culture results & Patient's Number \\
\hline 1 & Scanty & 3 \\
\hline 2 & $1+$ & 14 \\
\hline 3 & $2+$ & 14 \\
\hline 4 & $3+$ & 70 \\
\hline & Total & 101 \\
\hline
\end{tabular}

$\mathrm{ZN}$ microscopy results for the $94 \mathrm{~TB}$ positive samples were scanty for 2 samples, 1+ for 25 samples, 2+ for 27 samples and $3+$ for 40 samples. Primary culture results for the 101 samples were scanty for 3 samples, $1+$ for 14 samples, 2+ for 14 samples and $3+$ for 70 samples [Table 2]. The minimum time required for the growth of Mycobacterium tuberculosis on Lowenstein - Jensen medium was 2 weeks and the maximum was 8 weeks.

By performing First-Line drug susceptibility testing, MDRTB was detected in a total of $37 / 101(36.63 \%)$ and $35 / 101$ $(34.65 \%)$ by both Proportion method and Nitrate Reductase 


\section{International Journal of Science and Research (IJSR) \\ ISSN (Online): 2319-7064 \\ Index Copernicus Value (2013): 6.14 | Impact Factor (2015): 6.391}

Assay respectively [Table 3]. By performing Second-Line drug susceptibility testing, one case of XDR-TB was detected by both Proportion method and NRA [Table 4]. The Nitrate Reductase Assay was easy to interpret. NRA results were available for 33 samples at day 7, 58 samples at day 10 and 10 samples at day 14 .

Table 3: Drug susceptibility testing results against FirstLine Drugs by the NRA compared to Proportion Method

\begin{tabular}{|c|c|c|}
\hline \multicolumn{2}{|c|}{ Susceptibility Test results for 101 M. tuberculosis strains } \\
\hline Drug Sensitivity Pattern & $\begin{array}{c}\text { Proportion } \\
\text { method }\end{array}$ & $\begin{array}{c}\text { Nitrate } \\
\text { Reductase } \\
\text { Assay }\end{array}$ \\
\hline Susceptible to RIF and INH & 47 & 47 \\
\hline RIF-Monoresistant & 8 & 7 \\
\hline INH-Monoresistant & 9 & 12 \\
\hline MDR (Resistant to RIF and INH) & 37 & 35 \\
\hline Total & 101 & 101 \\
\hline
\end{tabular}

Table 4: Drug susceptibility testing results against Second Line Drugs by the NRA compared to Proportion Method

\begin{tabular}{|c|c|c|}
\hline Drug Susceptibility Pattern & $\begin{array}{l}\text { Proportion } \\
\text { Method }\end{array}$ & $\begin{array}{c}\text { Nitrate Reductase } \\
\text { Assay }\end{array}$ \\
\hline Susceptible to K \& OF & 17 & 22 \\
\hline K-Monoresistant & 7 & 5 \\
\hline OF-Monoresistant & 13 & 10 \\
\hline XDR & 1 & 1 \\
\hline
\end{tabular}

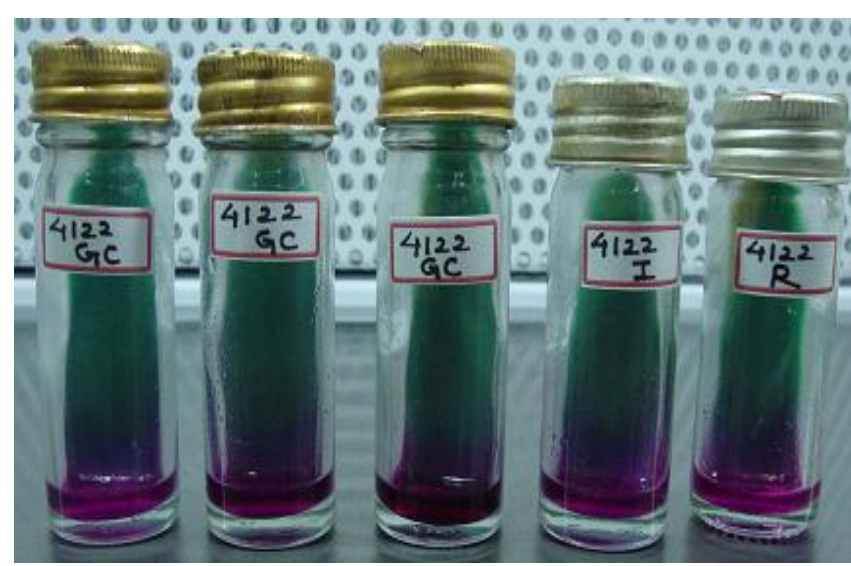

Figure 1: Drug susceptibility testing of M. tuberculosis for First Line Drugs by NRA

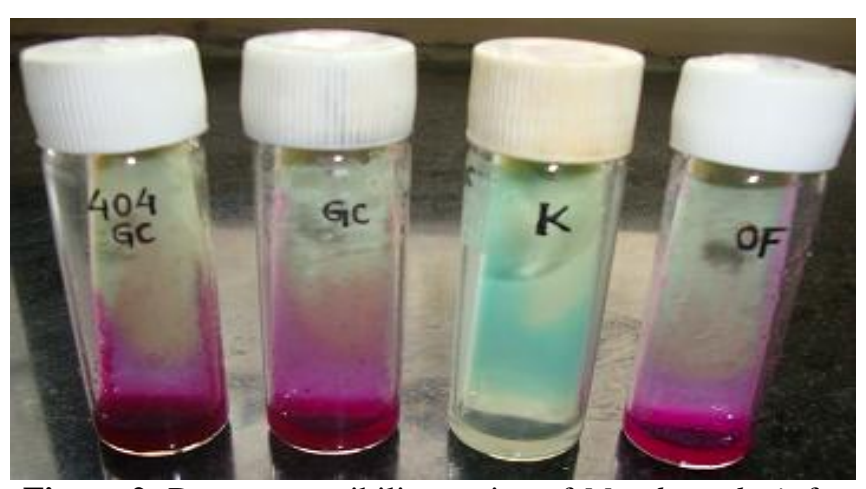

Figure 2: Drug susceptibility testing of $M$. tuberculosis for Second Line Drugs by NRA
Table 5: Sensitivity and Specificity for Rifampicin by NRA

\begin{tabular}{|c|c|c|c|c|}
\hline \multirow{4}{*}{$\begin{array}{c}\text { Nitrate } \\
\text { Reductase } \\
\text { Assay }\end{array}$} & RIF & \multicolumn{3}{|c|}{ Proportion Method } \\
\cline { 2 - 5 } & Positive & $7(\mathrm{TP})$ & $0(\mathrm{FP})$ & 7 \\
\cline { 2 - 5 } & Negative & $1(\mathrm{FN})$ & $93(\mathrm{TN})$ & 94 \\
\cline { 2 - 5 } & Total & 8 & 93 & 101 \\
\hline
\end{tabular}

Sensitivity of Rifampicin (RIF) $=\mathrm{TP} / \mathrm{TP}+\mathrm{FN} \times 100$, $7 / 7+1 \times 100=87.5 \%$

Specificity of Rifampicin (RIF) $=\mathrm{TN} / \mathrm{TN}+\mathrm{FP} \times 100$, $93 / 93+0 \times 100=100 \%$

As compared to Proportion method, the sensitivity of the NRA was found to be $87.5 \%$ and $100 \%$ whereas specificity of the NRA was found to be $100 \%$ and $96.73 \%$ for RIF and INH respectively.

The sensitivity of the NRA was found to be $71.42 \%$ and $76.92 \%$ whereas specificity of the NRA was found to be $100 \%$ and $100 \%$ for $\mathrm{K}$ and OF respectively.

\section{Discussion}

In recent years, a major emphasis has been given on rapid diagnosis and timely treatment of MDR-TB. Simple, efficient, fast and low cost methods for detection of drug resistant TB is highly desirable to cut the transmission of the disease. In this context, we evaluated the performance of Nitrate Reductase Assay in the rapid detection of multi-drug resistant and extensively-drug resistant tuberculosis in South Gujarat region.

This study shows that men are more commonly affected than women. It was also found that TB cases reported in most countries were higher in males than in females [15]. Our findings were found to be similar with Vanisree et al. (2014). In their finding, they reported out of 100 cases, 71 were males and 29 were females

Although considered as the gold-standard method, the drug susceptibility testing performed on $\mathrm{LJ}$ medium by the Proportion method is very slow and requires 4-6 weeks to produce the results.

The drug susceptibility results for the NRA were obtained within 7-14 days after isolation of the bacterium [16]. Similar time period is also taken by BACTEC TB-460 or MGIT methods with the disadvantage of requiring high cost equipment and radioactive substances [17]. In our study, the indirect NRA showed overall good sensitivity and specificity for the drugs Isoniazid, Rifampicin, Kanamycin and Ofloxacin to be tested. Many studies have also reported the importance of the NRA for determining susceptibility or

Volume 5 Issue 6, June 2016 www.ijsr.net 


\section{International Journal of Science and Research (IJSR) \\ ISSN (Online): 2319-7064}

Index Copernicus Value (2013): 6.14 | Impact Factor (2015): 6.391

resistance to rifampicin and isoniazid and have shown high sensitivity and specificity $[18,19,20]$. The accuracy for Rifampicin is an attractive feature of the NRA so it is used as a screening method for detection of MDR strains, as resistance to Rifampicin is a marker for MDR detection [21, 22]. The NRA also has the potential to be used for the detection of resistance to second line drugs. In 2005, Martin et al. reported the first evaluation of the NRA for the detection of ofloxacin resistance and found it to be in complete agreement with the proportion method [16].

Rosales et al. evaluated the NRA for the rapid detection of resistance to ofloxacin and kanamycin and found good specificity for both drugs, but lower sensitivity for detecting resistance to kanamycin which is in concordance with our results [23]. Our study confirms that the NRA can also be used to screen XDR-TB. But this study was limited by the relatively small number of XDR-TB cases found.

\section{Conclusion}

From the results of the present study, it can be concluded that the NRA is a simple, accurate, inexpensive and rapid method for detection of MDR and XDR-TB, especially in poor-resource countries, with limited laboratory facilities because it does not require expensive reagents and sophisticated equipments. The technique may become a valid substitute to traditional time consuming methods.

\section{References}

[1] Global Tuberculosis Report 2013 (2014). Technical Report Series, WHO/HTM/TB/2013.15. World Health Organization, Geneva, Switzerland.

[2] Chiang CY, Van Weezenbeek C, Mori T, Enarson DA (2013). Challenges to the global control of tuberculosis. Respirology; 18: 596-604.

[3] World Health Organization (2010) Multidrug and extensively drug-resistant TB (M/XDR-TB): global report on surveillance and response. WHO report 2010. WHO/HTM/TB/2010.3, Geneva, Switzerland. ISBN 9789241599191

[4] Harries AD, Lin Y, Satyanarayana S, Lönnroth K, Li L, et al. (2011). The looming epidemic of diabetesassociated tuberculosis: learning lessons from HIVassociated tuberculosis. Int J Tuberc Lung Dis 15: 14361444, i.

[5] Kent PT, Kubica GP. Public Health Mycobacteriology (1985). A Guide for the Level III Laboratory. Atlanta, GA: CDC

[6] Canetti G, Fox W, Khomenko A et al. (1969). Advances in techniques of testing mycobacterial drug sensitivity, and the use of sensitivity tests in tuberculosis control programmes. Bull World Health Organ. 41:21-43.

[7] Siddiqi, S., Ahmed, A., Asif, S., Behera, D., Javaid, M., Jani, J.,. \& Rüsch-Gerdes, S. (2012). Direct drug susceptibility testing of Mycobacterium tuberculosis for rapid detection of multidrug resistance using the Bactec MGIT 960 system: a multicenter study. Journal of clinical microbiology, 50(2), 435-440.

[8] Hillemann D, Rüsch-Gerdes S, Richter E. (2007). Evaluation of the Geno- Type MTBDRplus assay for rifampin and isoniazid susceptibility testing of
Mycobacterium tuberculosis strains and clinical specimens. J. Clin. Microbiol. 45:2635-2640.

[9] Golyshevskaia VI, Korneev AA, Chernousova LN, Selina LG, Kazarova TA, Grishina TD et al. (1996) [New microbiological techniques in diagnosis of tuberculosis]. Probl Tuberk. 6: 22-5 [Russian].

[10] Angeby KA, Klintz L, Hoffner SE (2002). Rapid and inexpensive drug susceptibility testing of Mycobacterium tuberculosis with a nitrate reductase assay. J Clin Microbiol.40: 553-5.

[11]WHO. Strategic and Technical Advisory Group for Tuberculosis (STAG-TB). Report of the Ninth Meeting. http://www.who.int/tb/advisory_bodies/

stag_tb_report_2009.pdf (4 June 2013, date last accessed).

[12]RNTCP, Manual of Standard Operating Procedures (SOP) web address

[13] Centro Panamericano de Zoonosis. Tuberculosis bacteriology (1988). Technical note 11. Buenos Aires: Centro Panamericano de Zoonosis,[Spanish].

[14] http://www.tbcindia.nic.in/pdfs.

[15] Dye C (2006). Global epidemiology of tuberculosis, Lancet, 367, 938-940

[16] Martin, A.; Palomino, J.C.; Portaels, F. (2005). Rapid detection of ofloxacin Resitance in Mycobacterium tuberculosis by Two Low- Cost Colorimetric Methods: Resazurin and Nitrate Reductase Assays. J. Clin. Microbiol., 43 (4), 1612-1616

[17] Montoro, E.; Lemus, D.; Echemendia, M.; Martin, A.; Portaels, F.; Palomino, J.C. (2005). Comparative evaluation of the nitrate reduction assay, the MTT test, and the resazurin microtitre assay for drug susceptibility testing of clinical isolates of Mycobacterium tuberculosis. J. Antimicrob. Chemother., 55 (4), 500505.

[18] Lemus D, Montoro E, Echemendi'a M et al. (2006). Nitrate reductase assay for detection of drug resistance in Mycobacterium tuberculosis: simple and inexpensive method for low-resource laboratories. J Med Microbiol. 55: 861-3.

[19] MartinA, Portaels F, PalominoJC (2007). Colorimetric redox-indicator methods for the rapid detection of multidrug resistance in Mycobacterium tuberculosis: a systematic review and meta-analysis. J Antimicrob Chemother. 59: 175-83.

[20] Shin SS, Asencios L, Yagui M et al. (2012). Impact of rapid drug susceptibility testing for tuberculosis: program experience in Lima, Peru. Int $\mathbf{J}$ Tuberc Lung Dis. 16: 1538-43.

[21] Coll, P. (2003). Fármacos con actividad frente Mycobacterium tuberculosis. Enferm Infecc. Microbiol. Clín., 21 (6), 299-308.

[22] Telenti, A.; Imboden P.; Marchesi, F.; et al. (1993). Detection of rifampicin resistance mutations in Mycobacterium tuberculosis. Lancet. 341 (10), 647-650.

[23] Rosales S, Pineda-Garc1'a L, Andino N et al. (2009) Evaluation of the nitrate reductase assay for rapid detection of extensively drug-resistant tuberculosis. Int J Tuberc Lung Dis 2009; 13: 1542-9. 